Original Research Article

\title{
Epidemiology and demographics of head and neck cancers: a hospital based retrospective study in Andhra Pradesh
}

\author{
A. Kusumanjali ${ }^{1}$, Niveditha M. ${ }^{2}$, Grace Vandana Jyothi R. ${ }^{3}$, Chaitanya V.K. ${ }^{4}$ \\ ${ }^{1}$ Dr. A. Kusumanjali, Assistant Professor, ${ }^{2}$ Dr. Niveditha Meenuga, Post-Graduate Resident, ${ }^{3}$ Dr. Grace Vandana Jyothi R., Post- \\ Graduate Resident, ${ }^{4}$ Dr. V. Krishna Chaitanya, Professor; all authors are affiliated with Department of Otorhinolaryngology, \\ Narayana Medical College, SPS Nellore, Andhra Pradesh, India.
}

Corresponding Author: Dr. A. Kusumanjali, Assistant Professor, Department of Otorhinolaryngology, Narayana Medical College, SPS Nellore, Andhra Pradesh, India. E-mail: drkusumanjali@gmail.com

\begin{abstract}
Background: Head and Neck cancers (HNC) in India make up 25-30 percent of all cancers and are the most common cancer in Indian men and the third most common cancer in women. The aim of this study was to study the demographic profile, sites involved and the histopathological patterns of $\mathrm{HNC}$ at a tertiary care hospital in Sri Potti Sriramulu Nellore district, Andhra Pradesh. Materials and Methods: This was a retrospective study conducted in Department of Otolaryngology, Narayana Medical College and Hospital, SPS Nellore, Andhra Pradesh. The data was collected from the years 2015 to 2018 . Only histopathologically confirmed cases of malignancies of Head and Neck were included in the study. Results: A total of 75 cases were included in the study. There were $53(70.66 \%)$ male and $22(29.33 \%)$ female patients. The mean age of male and female patients was $56.45 \pm 11.46$ and $51.68 \pm 9.20$ years respectively. The most common sites HNC, in both male and female patients, were found to be larynx (36\%) followed by oral cavity (33.33\%). It was also observed that squamous cell carcinoma (SCC) was the most common histopathological variant amongst all the HNC. All the patients in this study had one or more associated risk factors for HNC. Conclusion: There is a spurt of HNC cases in SPS Nellore. It is important to focus on prevention and early detection of $\mathrm{HNC}$ and also have a dedicated cancer hospital to cater the needs of the patients.
\end{abstract}

Keywords: Epidemiology, Demography, Head and Neck Cancers, Risk Factors, Andhra Pradesh.

\section{Introduction}

The burden of cancer is rising in both developed and developing countries. This is because of the aging population and lifestyle changes such as smoking and physical inactivity [1]. Cancer rates and patterns vary according to geographical locations. India, in the $21^{\text {st }}$ century has emerged as one of the rapidly growing economies across the globe which also has brought changes in lifestyle, in fact is partly responsible for the growing cancer load [2,3]. India has around 2.25 million cases of cancer with over one lakh new cases being registered every year, according to a statement released by Cancerindia.org in 2018 [4]. It is also a disturbing prediction that these numbers are expected to be almost double as a result of demographic changes alone by 2040 [5]. The major sites of cancer in the developed countries are breast, colorectal, pancreas, prostate, and lung, whereas, head and neck are the primary sub-sites in India, make up 25-30 percent of all cancer sites, compared to 3-4 percent in the Western World [6,7]. Moreover, Head and Neck cancers (HNC) are the

Manuscript received: $10^{\text {th }}$ November 2019

Reviewed: $20^{\text {th }}$ November 2019

Author Corrected: $25^{\text {th }}$ November 2019

Accepted for Publication: 29 $9^{\text {th }}$ November 2019 most common cancer in Indian men and the third most common cancer in women, according to population-based cancer registries [8]. The American Joint Committee on Cancer, head and neck oncology defines $\mathrm{HNC}$ as malignancies arising from mucosal surfaces from the oral cavity, pharynx, larynx, and paranasal sinuses, and cancers originating from major and minor salivary glands [9].

Tobacco and alcohol are considered the most common independent and combined risk factors associated with HNC [10]. Other risk factors reported include poor oral hygiene and human papillomavirus (HPV) $[11,12]$. In South Asian countries, the risk of $\mathrm{HNC}$ is further aggravated by smoking of bidis, reverse smoking, and chewing tobacco, betel quid, and areca nut [13]. The epidemiology and the histopathological types of HNC have been widely studied but very few studies have been done in South India. Hence, this study, was planned to study the demographic profile, sites involved and the histopathological patterns of $\mathrm{HNC}$ at a tertiary care hospital in Sri Potti Sriramulu Nellore (SPS Nellore) district which is located in the state of Andhra Pradesh. 


\section{Original Research Article}

\section{Material and Methods}

Study Site: The study was conducted in Department of Otorhinolaryngology, Narayana Medical College and Hospital, SPS Nellore, Andhra Pradesh.

Study Design: This was a retrospective study

Duration of Study: The data was collected from the years 2015 to 2018 .

\section{Inclusion Criteria}

1. Age $\geq 18$ years.

2. Either Gender.

3. Histopathologically confirmed cases of malignancies of Head and Neck.

\section{Exclusion Criteria}

1. Pre-Malignant Lesions.

2. Secondary malignancies.

\section{Results}

A total of 75 cases of histopathologically confirmed HNC cases were included in the study. Amongst the patients, there were 53 (70.66\%) male and $22(29.33 \%)$ female patients. The age of male and female patients ranged from 23 to 78 years and 35 to 68 years with Mean $\pm \mathrm{SD}$ as $56.45 \pm 11.46$ years and $51.68 \pm 9.20$ years respectively. The difference in mean age between males and females was statistically not significant ( $\mathrm{t}$-test $\mathrm{P}=0.0875)$. After the stratification of the patients in different age groups, it was observed that the highest percent of males were in the 61-70 years' age group, whereas, females were the highest in the 5160 years' age group (Table 1). It was also observed that there was no statistically significant difference between either gender across all age groups except between 31-40 years (Table 1).

Table-1: Demographic characteristics of HNC cases.

\begin{tabular}{|c|c|c|c|c|c|}
\hline \multicolumn{2}{|c|}{ Age Group } & \multicolumn{4}{|c|}{ Gender } \\
\hline & $\begin{array}{l}\text { Total } \\
\text { n (\%) }\end{array}$ & $\begin{array}{l}\text { Males } \\
\text { n (\%) }\end{array}$ & $\begin{array}{c}\text { Females } \\
\text { n (\%) }\end{array}$ & $95 \%$ CI & P value \\
\hline$\leq 30$ years & $2(2.67)$ & $2(3.77)$ & $0(0)$ & $-11.34 \%$ to $12.75 \%$ & NS \\
\hline $31-40$ years & $9(12.00)$ & $3(5.66)$ & $6(27.27)$ & $4.47 \%$ to $42.82 \%$ & 0.0092 \\
\hline 41-50 years & $9(12.00)$ & $5(9.43)$ & $4(18.18)$ & $-6.59 \%$ to $29.77 \%$ & NS \\
\hline 51-60 years & $24(32.00)$ & $17(32.08)$ & $7(31.82)$ & $-23.32 \%$ to $20.72 \%$ & NS \\
\hline $61-70$ years & $27(36.00)$ & $22(41.51)$ & $5(22.73)$ & $-5.28 \%$ to $37.17 \%$ & NS \\
\hline$>70$ years & $4(5.33)$ & $4(7.55)$ & $0(0)$ & $-8.01 \%$ to $17.86 \%$ & NS \\
\hline
\end{tabular}

The most common sites HNC, in both male and female patients, were found to be larynx (36\%) followed by oral cavity (33.33\%) (Table 2).

In the oral cavity, it was observed that $18(72 \%)$ patients had lesions over the tongue and the rest had lesions over the buccal mucosa. In $16 \%$ of patients, the lesions were present in the hypopharynx while a few of the patients had lesions in the oropharynx, neck, nose, ear and on the face (Table 2).

It was also observed that squamous cell carcinoma (SCC) was the most common histopathological variant amongst all the HNC at $80 \%$ and there was statistically significant difference noted between SCC and Non-SCC cases $(p<0.001)($ Table 2$)$.

Available online at: www.medresearch.in 447|P a g e 
Table-2: Distribution of HNC cases based on site of disease and histopathology.

\begin{tabular}{|c|c|c|c|}
\hline Site & \multicolumn{3}{|c|}{ n (\%) } \\
\hline Larynx & \multicolumn{3}{|c|}{$27(36.00)$} \\
\hline Oral Cavity & \multicolumn{3}{|c|}{$25(33.33)$} \\
\hline Hypopharynx & \multicolumn{3}{|c|}{$12(16.00)$} \\
\hline Oropharynx & \multicolumn{3}{|c|}{$4(5.33)$} \\
\hline Neck & \multicolumn{3}{|c|}{$3(4.00)$} \\
\hline Nose & \multicolumn{3}{|c|}{$2(2.67)$} \\
\hline Ear & \multicolumn{3}{|c|}{$1(1.33)$} \\
\hline Face & \multicolumn{3}{|c|}{$1(1.33)$} \\
\hline \multicolumn{4}{|c|}{ Histopathology } \\
\hline $\begin{array}{l}\text { SCC } \\
\text { n (\%) }\end{array}$ & $\begin{array}{c}\text { Non-SCC } \\
\text { n }(\%)\end{array}$ & $95 \%$ CI & $P$ value \\
\hline $60(80.00)$ & $15(20.00)$ & $45.27 \%$ to $70.59 \%$ & $<0.001$ \\
\hline
\end{tabular}

A trend line was plotted to observe increase in the number of cases year on year from 2015 and it was observed that there was a linear rise in the number of cases of $\mathrm{HNC}$ at our institute during the study period (Figure 1).

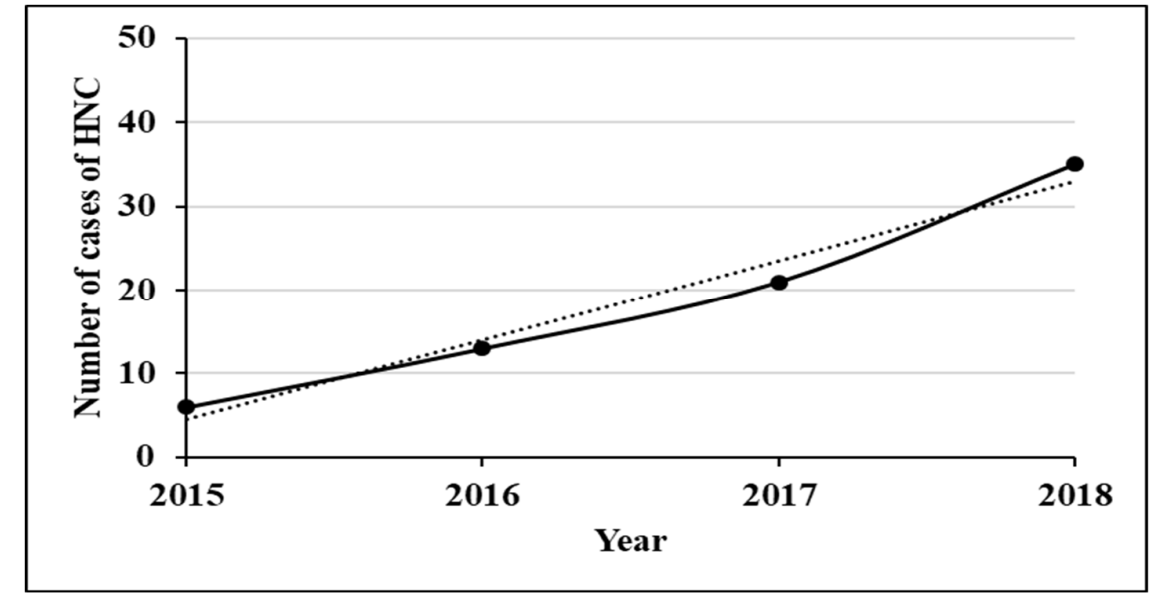

Fig-1: Trend chart of the HNC cases during the study period.

All the patients in this study had one or more associated risk factors for HNC. The most common risk factors observed were tobacco chewing, tobacco smoking, betel quid, and alcohol consumption.

\section{Discussion}

This is a retrospective study conducted by the department of Otorhinolaryngology at Narayana Medical College and Hospital situated at SPS Nellore district, Andhra Pradesh. Our Institute is a medical teaching hospital which is a referral hospital for the entire SPS Nellore district.

In the current study, it was observed that the male: female ratio was 2.4:1. Majority of patients presenting with $\mathrm{HNC}$ were above 50 years of age in both males and females. The findings of our study are similar to the previously done studies in the states of Andhra Pradesh and Bihar where it was observed that the male: female ratio of $\mathrm{HNC}$ was $1: 1-$ 3.1:1 [14,15]Error! Bookmark not defined.. Worldwide, most studies had documented that HNSCC mostly occurred in males and the male predominance is also apparent in all age groups [16]. From the observations in this study, it can be inferred that the disease burden of $\mathrm{HNC}$ is more in males than in females. This could be due to the fact that tobacco chewing was the common in males as observed in this study. In some male patients, there was a combination of tobacco chewing along with smoking and alcohol addiction. However, in female patients, tobacco chewing was the most common risk factor observed. Smoking and alcohol addiction were uncommon. It could also be possibly due to the fact that males had the risk factors over a long time and more quantity, when compared to females.

Larynx (36\%) was the most common site of HNC followed by oral cavity (33.3\%) in this study. The most common subsite involved in the oral cavity was the tongue followed by 


\section{Original Research Article}

buccal mucosa which is a clear association to the use of tobacco especially in the form of chewing. The results of this study are similar to findings in other studies conducted in different geographical locations of India. In a study conducted Rekha et al in the undivided state of Andhra Pradesh in the year 2011 which included 800 cases of HNC, carcinoma of larynx was the commonest cancer reported [14]. Similar findings were observed in another study by Siddiqui et al in Bihar where larynx was the most common site for malignancy and the supraglottic region being the most commonly affected sub-site [15].

Whereas, in a study conducted in Uttar Pradesh which included 850 patients of $\mathrm{HNC}$, it was observed that 279 (32.82\%) patients had cancer of the oral cavity followed by oropharynx in 271 (31.88) patients [17]. In a study conducted in the Northeast parts of India which included 2052 cases of all malignancies, it was observed that 1118 had $\mathrm{HNC}$ and the commonest $\mathrm{HNC}$ was oropharyngeal carcinoma comprising of 320 cases (28.62\%) [18]. In another retrospective study in Meghalaya, oropharyngeal cancer was the commonest site involved amongst the HNC patients which accounted for $24.2 \%$ [19].

HNCs specifically arise from the epithelium lining the oral cavity, pharynx, sinonasal region, nasal cavity and larynx [20]. Squamous cell carcinoma is by far the most important and the most common malignant mucosal neoplasm of the head and neck accounting for over $90 \%$ of all malignancies [21]. Squamous cell carcinoma begins as squamous dysplasia, which constitutes changes of the surface epithelium that precede the invasion of the subepithelial connective tissue. The dysplasia can be graded into three categories depending on the degree of epithelial atypia. Mild dysplasia is associated with the lower one-third of the epithelium. When two-thirds of the epithelium is affected, this finding is considered moderate dysplasia. Carcinoma in situ or severe dysplasia occurs when the atypia involves the full thickness of the epithelium. Subsequently, carcinoma in situ may progress to invasion of the subepithelial connective tissue and extend to the skeletal muscles, bone and skin [21].

The HNCs are also heterogeneous with different patterns of behavior and presentation [22]. In our study, SCC was the most common histopathological variant of $\mathrm{HNC}$ which was observed in $80 \%$ of cases. Our findings are close to various studies published which observed that squamous cell carcinoma varies from $88 \%$ to $96 \%$ [23]. Although SCC is most common, neoplasms of mesenchymal, neural, and other cellular origins do occur [24]. Similarly, other histological variants were also observed in our study. In this study, it was observed that all the patients had one or more associated risk factors mainly in the form of tobacco or alcohol consumption for more than five years at the time of presentation. Burning tobacco releases polycyclic aromatic hydrocarbons, which are known carcinogens. These carcinogens reach epithelial surfaces through smoke or get dissolved in saliva. Breakdown of these carcinogens by aryl hydrocarbon hydroxylase produces the actual carcinogenic epoxides that bind to the DNA and RNA molecules [25]. Tobacco along with alcohol consumption increases the risk of HNC. Alcohol is itself an independent risk factor for HNC. The International Agency for Research on Cancer (IARC) listed both alcohol beverages and acetaldehyde, its major metabolite, as human carcinogens in 2012 [26].

The carcinogenic effects of ethanol and acetaldehyde in humans may be caused by DNA synthesis damage and repair resulting in structural and functional changes [27]. The other proposed mechanisms of alcohol as an independent risk factor for $\mathrm{HNC}$ include generation of reactive oxygen species leading to oxidative stress and 10100 higher fold concentration of acetaldehyde in the saliva when compared to blood $[28,29]$. Another established risk factor for HNC is Human Papilloma Virus (HPV). The mechanism of HPV related cancer is thought to be by increase in viral oncoprotein activity and individual variations in protein expression, and genetic and epigenetic alterations [30]. However, in our study we did not observe any of our patients having HPV infection. The findings of our study are similar to published literature where the authors observed that the incidence of HPV related HNC are relatively rare in India [31].

As per the 2011 census, the population of SPS Nellore district was over five lakhs [32]. However, due to rapid urbanization the population in this district would be much higher currently. In our study, it can be observed that there is almost six-fold rise in the number of $\mathrm{HNC}$ cases presenting to our hospital in the year 2018 compared to the year 2015 clearly showing a spurt in HNC in the district.

This rapidly increase in number of HNC pose challenges for the policy makers and the health care providers in preventing and management of HNC. Overall, Head and neck cancer in India has distinct demographic profile, risks factors, food habits, and personal and family history. HNCs are emerging as major lifestyle-related public health issues in India that have a long latent duration and need dedicated treatment facilities and human resources.

Moreover, HNC prognosis has not experienced a considerable enhancement, despite the advancements and great strides that have been made in recent decades. This could be due to the fact that managing head and neck cancers in India is somewhat different, as compared to the west. The major shortcoming is to cope up, with the loss to follow-up, which makes the task of conducting and reporting the end results of clinical trials difficult. 
Original Research Article

There are certain limitations to this study. The first limitation is that the research was conducted in only one institution and the second one is that the study has only four years of data collection.

\section{Conclusion}

Head and neck cancers are a major problem in India, primarily due to the heavy use of tobacco products. With many head and neck cancers preventable, emphasis should be on preventing the disease and also detection at an early stage. It is also vital to overcome the challenges in the management of HNC mainly in the form of socioeconomic constraints, large patient population, scarcity of trained health workers, and inadequate infrastructure. Moreover, the state of Andhra Pradesh is devoid of a dedicated government cancer hospital to cater to the patients and would take considerable time to establish one. Hence, it is suggested to have a unified systemic framework for collaboration of cancer centres across India to form a National Cancer Grid and aim to overcome these challenges and provide standard care to all patients across the country.

\section{What the study adds to the existing knowledge?}

This rapid increase in the number of cases requires streamlined cancer reporting and information system for better management. Therefore, the results of this study would be useful in generating data on $\mathrm{HNC}$ and also add to the information for cancer registry of the newly bifurcated state of Andhra Pradesh.

\section{Author's contribution}

Dr. A. Kusumanjali: Conceived and designed the study and manuscript preparation

Dr. V. Krishna Chaitanya: Conceived and designed the study

Dr. Niveditha M.: Data collection

Dr. Grace Vandana Jyothi R.: Collected data

Funding: No funding sources

Conflict of interest: None declared

Ethical Approval: This study was approved by the Institutional Ethics Committee.

\section{References}

1. Mathers C. The global burden of disease: 2004 update. World Health Organization; 2008.

1.Reddy KS, Shah B, Varghese C, Ramadoss A. Responding to the threat of chronic diseases in India. The Lancet. 2005;366(9498):1744-1749. doi: 10.1016/S01406736 (05)67343-6.
2. India. Office of the Registrar General, University of Toronto. Centre for Global Health Research. Report on Causes of Death in India, 2001-2003. Office of the Registrar General India in collaboration with Centre for Global Health Research, St. Michael's Hospital, University of Toronto; 2009.

3. Cancer Statistics Available at: http://cancerindia. org.in/ cancer-statistics/.

4. WHO: Global Cancer Observatory, International Agency for Research on Cancer. Available at https://gco.iarc.fr/.

5. Siegel RL, Miller KD, Jemal A. Cancer statistics, 2016. CA: A Can J Clinic. 2016;66(1):7-30. doi: 10.3322/ caac. 21332.

6. Gatta G, Botta L, Sánchez MJ, Anderson LA, Pierannunzio D, Licitra L, et al. Prognoses and improvement for head and neck cancers diagnosed in Europe in early 2000s: The EUROCARE-5 populationbased study. Europe J Cancer. 2015;51(15):2130-2143. doi: 10. 1016/j.ejca.2015.07.043.

7. Asthana S, Patil RS, Labani S. Tobacco-related cancers in India: A review of incidence reported from populationbased cancer registries. Indian J Med Paediatr Oncol: J Indian Soc Med Paediatr Oncol. 2016;37(3):152. doi: 10. 4103/ 0971-5851.190357.

8. Lydiatt WM, Patel SG, O'Sullivan B, Brandwein MS, Ridge JA, Migliacci JC, et al. Head and neck cancersmajor changes in the American Joint Committee on cancer eighth edition cancer staging manual. CA: Cancer J Clinic. 2017; 67(2):122-137. doi: 10.3322/caac.21389.

9. Blot WJ, McLaughlin JK, Winn DM, Austin DF, Greenberg RS, Preston-Martin S, et al. Smoking and drinking in relation to oral and pharyngeal cancer. Cancer Res. 1988;48(11):3282-3287.

10. Guha N, Boffetta P, Wünsch Filho V, Eluf Neto J, Shangina $\mathrm{O}$, Zaridze $\mathrm{D}$, et al. Oral health and risk of squamous cell carcinoma of the head and neck and esophagus: results of two multicentric case-control studies. Am J Epidemiol. 2007;166(10):1159-1173. doi: 10.1093/ aje/kwm193.

11. Kreimer AR, Clifford GM, Boyle P, Franceschi S. Human papillomavirus types in head and neck squamous cell carcinomas worldwide: a systematic review. Cancer Epidemiol Prevent Biomark. 2005;14(2):467-475. doi: 10 1158/ 1055-9965.EPI-04-0551.

12. IARC Working Group on the Evaluation of Carcinogenic Risks to Humans. Betel-quid and areca-nut chewing and some areca-nut derived nitrosamines. IARC monographs on the evaluation of carcinogenic risks to humans. 2004; 85:1. 
Original Research Article

13. Rekha R, Reddy MV, Reddy PP. Epidemiological studies of head and neck cancer in South Indian Population. Res Cancer Tumor. 2013;2(2):38-44. doi:10.5923/j. rct. 20130202.04.

14. Siddiqui M, Chandra R, Aziz A, Suman S. Epidemiology and histopathological spectrum of head and neck cancers in Bihar, a state of Eastern India. Asian Pacific J Cancer Prevent. 2012;13(8):3949-3953. doi: 10.7314/ apjcp. 2012.13.8.3949.

15. Dasgupta S, Chakrabarti S, Deb AR. Clinicopathological profile of head and neck squamous cell carcinoma. Indian J Med Paediatr Oncol. 2019;40(3):369373. doi: 10.4103/ijmpo.ijmpo 180_17.

16. Alam MS, Siddiqui SA, Perween R. Epidemiological profile of head and neck cancer patients in Western Uttar Pradesh and analysis of distributions of risk factors in relation to site of tumor. $\mathrm{J}$ Cancer Res Therapeut. 2017;13(3):430. doi: 10.4103/0973-1482.180687.

17. Bhattacharjee A, Chakraborty A, Purkaystha P. Prevalence of head and neck cancers in the north east-an institutional study. Indian J Otolaryngol Head Neck Surg. 2006;58(1):15-19. doi: 10.1007/BF02907731.

18. Shunyu NB, Syiemlieh J. Prevalence of head and neck cancer in the state of Meghalaya: Hospital-based study. Int J Head Neck Surg. 2013;4(1):1-5.

19. Pai SI, Westra WH. Molecular pathology of head and neck cancer: implications for diagnosis, prognosis, and treatment. Ann Rev Pathol: Mec Dis. 2009; 4:49-70. doi: 10.1146/annurev.pathol.4.110807.092158.

20. Pathak J, Swain N, Patel S, Poonja LS. Histopathological variants of oral squamous cell carcinoma-institutional case reports. J Oral Maxillofac Pathol: JOMFP. 2014;18(1):143. doi: 10.4103/0973-029X. 131945.

21. Forastiere A, Koch W, Trotti A, Sidransky D. Head and neck cancer. New Eng J Med. 2001;345(26):1890-900. doi: 10.1056/NEJMra001375.
22. Mehrotra R, Singh M, Gupta RK, Singh M, Kapoor AK. Trends of prevalence and pathological spectrum of head and neck cancers in North India. Indian J Cancer. 2005; 42(2): 89. doi: 10.4103/0019-509x.16698.

23. Cohen N, Fedewa S, Chen AY. Epidemiology and demographics of the head and neck cancer population. Oral Maxillofac Surg Clinic. 2018;30 (4):381-395. doi: 10. 1016/j. coms. 2018.06.001.

24. Hoffmann D, Hecht SS, Ornaf RM, Wynder EL, Tso TC. Chemical studies on tobacco smoke. XLII. Nitrosonornicotine: presence in tobacco, formation and carcinogenicity. IARC scientific publications. 1976;(14): 307-320.

25. IARC Working Group. (2012). Consumption of alcoholic beverages. Lyon: International Agency for Research on Cancer.

26. Seitz HK, Stickel F. Molecular mechanisms of alcoholmediated carcinogenesis. Nature Rev Cancer. 2007;7(8): 599. doi: $10.1038 / \mathrm{nrc} 2191$.

27. Garro AJ, Espina N, Farinati F, Salvagnini M. The effects of chronic ethanol consumption on carcinogen metabolism and on O6-methylguanine transferasemediated repair of alkylated DNA. Alcoholism: Clinic Experiment Res. 1986;10(6):73S-77S.

28. Seitz H. K., Stickel F. Risk factors and mechanisms of hepatocarcinogenesis with special emphasis on alcohol and oxidative stress. Biol Chemi. 2006;387(4):349-360. doi: 10.1515/ BC.2006.047.

29. Wagner S, Sharma SJ, Wuerdemann N, Knuth J, Reder H, Wittekindt C, Klussmann JP. Human papillomavirusrelated head and neck Cancer. Oncol Res Treat. 2017;40(6): 334-340. doi: 10.1159/000477252.

30. Dandekar M, Tuljapurkar V, Dhar H, Panwar A, D Cruz AK. Head and neck cancers in India. J Surg Oncol. 2017; 115(5):555-563. doi: 10.1002/jso.24545.

31. Nellore City Census 2011 data Available at https:// www.census2011.co.in/census/city/416-nellore.html

\section{How to cite this article?}

A. Kusumanjali, Niveditha M, Grace Vandana Jyothi R, Chaitanya V.K. Epidemiology and demographics of head and neck cancers: a hospital based retrospective study in Andhra Pradesh. Trop J Ophthalmol Otolaryngol.2019;4(7):446-451. doi:10.17511/jooo.2019.i07.08 